\title{
De la Fábrica de Porcelana a la Escuela de Agrónomos de Madrid
}

Jara Muñoz Hernández

Universidad Politécnica de Madrid 



\title{
De la Fábrica de Porcelana a la Escuela de Agrónomos de Madrid
}

\section{From the Porcelain Manufactory to the School of Agronomists in Madrid}

Jara Muñoz Hernández ${ }^{1}$

Universidad Politécnica de Madrid

jara.munoz@upm.es

Fecha de recepción: 16 de noviembre de 2018

Fecha de aceptación: 20 de octubre de 2020

\section{Resumen}

La actual Ciudad Universitaria de Madrid se sitúa sobre el que fue uno de los Reales Sitios madrileños, el de La Florida y La Moncloa. Este artículo tiene como objeto contestar a la pregunta ¿qué había antes?, centrándose en el edificio de la Real Fábrica de Porcelana, que posteriormente se convertiría en el primer edificio universitario de la zona, la Escuela de Ingenieros Agrónomos, antes de que el campus siquiera se imaginase. Se enfoca, además, el trabajo no solo desde el punto de vista histórico, sino también desde el análisis arquitectónico, y se utiliza el dibujo como instrumento metodológico para establecer hipótesis que nos permitan comprender cómo fue ese lugar y cómo se ha transformado hasta llegar al edificio que conocemos hoy día.

Palabras clave: Real Fábrica de Porcelana de La Moncloa; Escuela de Ingenieros Agrónomos (Madrid); Dibujo; Arquitectura universitaria; Enseñanza agrícola; Difusión del patrimonio.

\begin{abstract}
Madrid's Ciudad Universitaria is located on the grounds of the ancient La Florida and La Moncloa Real State, which was one of the madrilian royal properties.
\end{abstract}

1 La autora de este artículo ha contado con un contrato predoctoral FPU financiado por el Ministerio de Educación, Cultura y Deporte (FPU15/01782). 
This article aims to answer the question what was there before?, focusing on the building of the Royal Porcelain Manufacture. It would later become the first university building in the area -the School of Agricultural Engineers-, even before the campus was envisaged. We approach this work not only from a historical perspective, but also from the architectural analysis, using drawing as a tool to understand how this place was and how it developed towards the current building we know today.

Keywords: Royal Porcelain Manufactory of La Moncloa; School of Agricultural Engineers (Madrid); University architecture; Agricultural education; Heritage dissemination.

\section{INTRODUCGIÓN. UN EDIFICIO PARA LA EDUCACIÓN AGRÍCOLA EN EL PREGAMPUS DE MADRID}

La Moncloa es uno de esos lugares madrileños que, en parte olvidado y en parte desconocido, se han ido rodeando de un halo de misterio e idealización. La Ciudad Universitaria llegó para muchos a este territorio como un proyecto invasivo que se imponía sobre un frondoso parque. Esto no era exactamente así, pero es cierto que durante las últimas décadas del siglo XIX y las dos primeras del XX, antes de que el proyecto del campus se materializara, la antigua finca real ${ }^{2}$ se había convertido en un lugar de asueto y disfrute de los madrileños.

Aunque en esos años había en La Florida-Moncloa múltiples instituciones, nos detendremos en una que se encontraba en el centro de la finca y que hoy todavía existe, si bien su extensión se ha visto mermada considerablemente: la Escuela de Ingenieros Agrónomos. Tras la revolución de la Gloriosa, el gobierno provisional decidió ceder La Florida al Ministerio de Fomento para instalar allí una Escuela de Agricultura (Figura 1), en lo que sería por fin, después del fracaso de la Escuela de Aranjuez (Muñoz, 2017), la materialización de múltiples intentos de instaurar la enseñanza de la agricultura en España.

De entre todos los edificios de La Moncloa que los agrónomos ocuparon, estudiaremos uno de ellos: la Fábrica de Porcelana ${ }^{3}$, construcción existente en La Moncloa desde la segunda década del siglo XIX, y seguiremos la vida del edificio desde su concepción como manufactura real hasta su demolición para construir una escuela de agricultura más amplia y moderna, que es la que parcialmente se conserva en la actualidad.

2 Como bibliografía general del Real Sitio de La Florida y la Moncloa, véanse Sancho (1995) y Fernández (1999).

3 Conviene hacer una observación acerca de los diversos nombres que este edificio ha recibido y que se emplearán a lo largo del artículo: Real Fábrica de Porcelana de La Moncloa, Fábrica de Loza fina de La Moncloa, Fábrica de Loza o Casa de la China. 


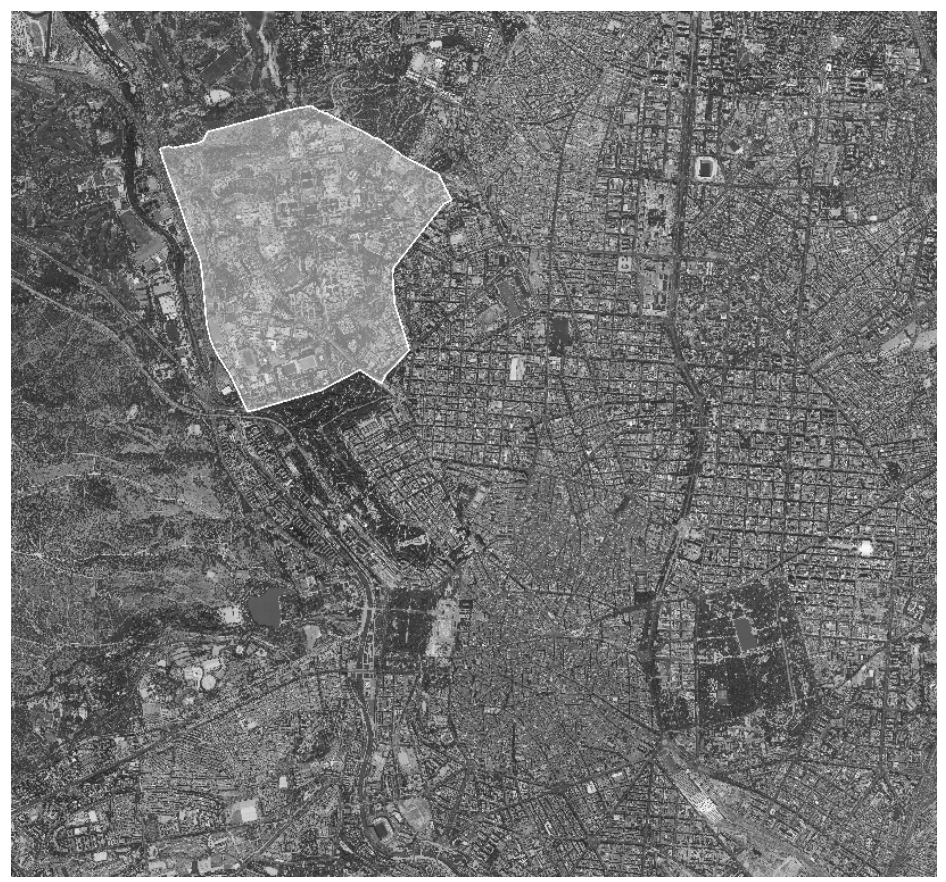

Figura 1. Situación del territorio de La Moncloa cedido señalado sobre la ortofoto de Madrid

Se tiene información del funcionamiento de la Fábrica de Porcelana ${ }^{4}$, pero no tanta de la construcción y morfología de su edificio, que, salvo por algunos planos, es bastante desconocido. Tampoco ha sido objeto de estudio tras su clausura y posterior ocupación por la Escuela de Agrónomos. A partir de varios planos inéditos hallados en el Archivo General de la Administración (en adelante AGA), planteamos cómo pudo ser la evolución de este edificio y aspiramos a completar las lagunas que sobre su vida existen.

\section{METODOLOGÍA}

Esta aportación busca aproximarse al edificio a través del dibujo, que se entiende como un instrumento científico para comprender y transmitir cómo fue la Fábrica y cómo se transformó a lo largo del tiempo. Para ello, se analiza la documentación original, ya sea gráfica o escrita, y se sintetiza en una base de datos gráfica, georreferenciada, que puede dar lugar a planimetrías completas, modelos

4 Contamos con la documentación original conservada en el Archivo General de Palacio (en adelante AGP); se han realizado, además, numerosos estudios del tema (Ordóñez, 1984; Sánchez, 1989; Seseña, 1995; Sierra y Tuda, 2000; Fernández, 2009...). 
tridimensionales e imágenes, en lo que entendemos como una reconstitución gráfica del objeto de estudio (Ortega et al., 2011, pp. 52-54).

En el caso que nos ocupa, la ausencia de información en alguno de los momentos históricos nos conduce a elaborar hipótesis sobre cómo ha sido la evolución de dicho lugar. Estudiaremos la Fábrica de Porcelana en cuatro momentos de su historia: 1870, que se toma como fecha del estado inicial que encuentra la Escuela de Agricultura al llegar al edificio, y que correspondería al plano de la propia manufactura cuando su uso era tal; 1885, momento en el que la Escuela había ocupado ya plenamente la Fábrica y llevado a cabo algunas obras de acondicionamiento; 1915, como fecha aproximada en la que se proyecta un nuevo edificio que sustituya al de la Fábrica de Porcelana, dado su mal estado de conservación; y 1925, cuando conviven en un mismo lugar las obras del nuevo edificio y el uso del antiguo como espacio de docencia.

Para el dibujo de estos cortes temporales, hemos empleado diversas fuentes gráficas históricas: el Plano del Real Sitio de La Florida y La Moncloa de la Junta de Estadística ( $c a$. 1865), planos de la Fábrica de Porcelana conservados en el AGP, las hojas kilométricas dibujadas entre 1870 y 1880, el plano de Facundo Cañada López de 1900, el de Pedro Núñez Granés de 1910 y el parcelario urbano de esa época, así como fotografías y diversos planos de reforma o situación encontrados en el AGA y la Escuela de Agrónomos (en adelante, ETSIAAB), acompañados, estos sí, en muchos casos, de sus correspondientes memorias, que suponen también un valioso aporte de información.

\section{LA REAL FÁBRICA DE PORGELANA DE LA MONCLOA}

Esta manufactura fue fundada en 1817 por Fernando VII, tras resultar destruida su homónima en el Retiro, como consecuencia de la guerra de la Independencia ${ }^{5}$. La Fábrica del Retiro se había convertido durante la contienda en un fortín y su situación topográfica, en una de las áreas de mayor cota de los jardines, había hecho de ella un punto de fácil referencia que se tradujo en su práctica total destrucción ${ }^{6}$. Tras quedar arrasada la manufactura, el nuevo rey tomó la decisión de trasladarla y construir una nueva en otro de los reales sitios madrileños, el de más reciente constitución: el Real Sitio de La Florida y La Moncloa.

5 Ya había habido un primer intento por parte de José I para construir una nueva fábrica en 1811, cuando en plena guerra probablemente fuera consciente de la próxima desaparición de la del Retiro. Según Real Decreto de 30 de septiembre de 1811, se dispondría de "un terreno proporcionado de bienes nacionales para establecer en él y poner corriente al público una fábrica de porcelana y loza fina" (Gaceta de Madrid, 5 de octubre de 1811, p. 1152).

6 La Fábrica de Porcelana del Buen Retiro fue volada por las tropas del ejército inglés en 1812. Hoy día son visibles algunos restos resultado de las excavaciones arqueológicas de 1996 (Marín et al., 1999, pp. 141-143). 
Esta propiedad de la Corona se ubicaba en la zona noroeste de la capital, formando una cuña que comenzaba en la Montaña del Príncipe Pío y se iba ensanchando hasta alcanzar las tapias de El Pardo. Su constitución se realizó durante el reinado de Carlos IV, a partir de la agregación de diversas parcelas y fincas previas (Sancho, 1995, pp. 648-649). Una de ellas, la de La Moncloa, en la que se encontraba el Palacete de La Moncloa, fue la que daría el nombre más adelante a todo este territorio.

Podemos establecer varias áreas dentro de la finca bastante diferenciadas entre sí: la zona oriental y central, más seca, estaba constituida por tierras dedicadas a la labranza y la ganadería. Se hallaba surcada de este a oeste por una serie de arroyos que con el discurrir del tiempo habían ido formando barrancos de diversa profundidad, siendo el más profundo de ellos el formado por el arroyo Cantarranas, que surcaba La Florida en su parte central. Otra zona era la más próxima a la vega del río Manzanares, que se traducía en una franja alargada de terreno que marcaba la cornisa madrileña en esta zona y recorría toda La Moncloa en su límite oeste. Era este un lugar mucho más húmedo y frondoso, y en el que tradicionalmente se habían instalado también huertos y viveros ${ }^{7}$. A lo largo de toda esta franja era donde se habían establecido pequeñas fincas de recreo de la clase alta madrileña (Añón, 1987, p. 15), que fueron las que el rey Carlos IV reunió hasta conseguir el total del conjunto ${ }^{8}$. Por último, al norte, varios pinares de diversa extensión marcaban ya la entrada al monte de El Pardo.

En este entorno, por tanto, fundamentalmente natural y con muy pocos elementos edificados, se instaló la nueva Fábrica de Porcelana, tras la vuelta al trono de Fernando VII. En cuanto al edificio propiamente dicho, aunque se dispone de escasa información tanto gráfica como escrita de la Granjilla de los Jerónimos, parece que se construyó aprovechando parte de la granja existente (Pérez-Villamil, 1904, p. 90). Por un lado, Antonio Forni, contador del Buen Retiro, y Joaquín García Rojo, teniente de arquitecto mayor, tras la orden del rey de reestablecer la Fábrica, proponían que se ubicara en el Real Sitio de La Florida (AGP, 10406/32): "para que se restablezca en pequeño la antigua Real Fábrica de Porcelana, se han visto los dos edificios que hay en proporción dentro de la Real Florida y pareciendo el más acomodado la Granjilla de los Gerónimos" (Sierra y Tuda, 2000, p. 119). Y García Rojo escribe una carta el 2 de julio de 1817 en la que relata su visita a La Florida "a fin de que reconociese la Casa-Labor titulada La Granjilla con el objeto de establecer en ella la Real Fábrica de la China". Por otro lado, si se observan los planos de la Fábrica de Porcelana, puede verse un conjunto formado a partir de la agregación de diversos cuerpos, en

7 En esta franja se había ubicado, por ejemplo, el primer jardín botánico de Migas Calientes, que fue el primero de Madrid hasta su traslado al Prado durante el reinado de Carlos III para fundar el Real Jardín Botánico.

8 Evidentemente, el nombre de La Florida es muy adecuado para esta exuberante zona, aunque se acabara empleando para denominar a la totalidad del territorio.

9 García Rojo describe también en este documento las reformas que se llevarán a cabo: "que haciendo las obras indicadas en el diseño adjunto, además un suelo en la planta baja señalada con 
lo que claramente no parece un proyecto planteado desde cero, sino que respondería más a una construcción que crece a lo largo del tiempo. Esto es aún más evidente en los alzados, en los que se puede entender perfectamente el cuerpo sur, donde se ubica la entrada principal, como un elemento con una presencia mayor, diferenciado del resto del conjunto. Además, en el plano de 1809 de Bentabole, que es previo a la construcción de la Fábrica de Loza-está dibujado durante la guerra de la Independencia marcando las posiciones militares-, podemos ver en el lugar que después ocupará la manufactura un edificio rectangular con dos patios, el oeste cerrado por sus cuatro caras y el este por tres de ellas, siendo el frente oriental el que queda abierto (Figura 2). Aunque es un plano a una escala mucho más lejana y por tanto apenas aporta detalle, no es arriesgado establecer como hipótesis que se reutilizó ese edificio y se incorporó un cuerpo delantero al sur, que transformó la planta rectangular en una en forma de L. El nuevo volumen añadido, dotado de un carácter más señorial, se convertiría en el principal y albergaría las dependencias reales y las de la dirección. La tipología del edificio, aunque no es evidente, sí podría apoyar esta hipótesis, pues tiene más que ver con la de una casa de campo o de labor, uso más cercano al que tendría con los Jerónimos, que con la de una fábrica de porcelana ex novo.

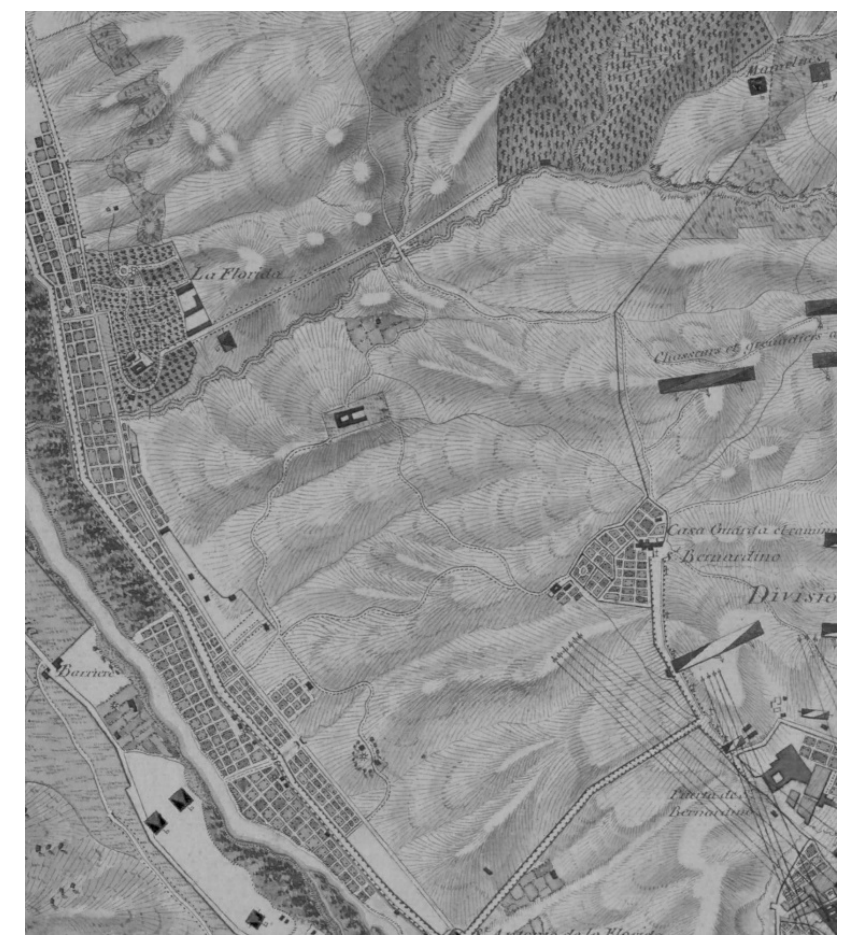

Figura 2. Plan de Madrid et de ses environs. 1809. Joseph Charles Marie Bentabole (detalle)

los números 3, 6 y 7 y las distribuciones de talleres y habitaciones en el piso bajo y principal, como igualmente las obras necesarias del horno, templadores..." (AGP, 10406/32). 
En los planos de toma de datos para el parcelario urbano dibujados entre 1860 y 1870 (Instituto Geográfico Nacional, 820521, 820522, 820527) se observa un edificio en forma de paralelogramo con un saliente en su fachada sur, que puede inscribirse completo en un rectángulo de 118x115 m, según explica también Madoz (1848, p. 401):

su planta es un paralelogramo con un ángulo entrante; linda por todos lados con terreno de S. M.; tiene su entrada y fachada principal al S. y de long. 246 pies, y el retablo que forma el ángulo entrante paralelo a este lado 204; la del E. tiene 384 y el retablo 84; la del N. 420 y la del O. $465^{10}$; formando una superficie en su totalidad de 178.776 pies cuadrados.

Respecto a su construcción, según Real Orden de 16 de diciembre de 1818, las obras estuvieron dirigidas por Joaquín García Rojo, ayudado por Pedro de Vargas, y se iniciaron junto con la construcción de un puente sobre el arroyo Cantarranas y una nueva cerca. Para estas obras se utilizó la piedra que había quedado en los restos del Buen Retiro (AGP Florida, 10389; Fernández, 1999, p. 304 y Puche y Mazadiego, 2000, p. 282). Prosigue Madoz (1848, p. 401) que la construcción de la Fábrica

es de mampostería el cimiento y zócalo de las fachadas exteriores, y lo restante hasta su total altura de fábrica de ladrillo con su armadura cubierta de teja. Consta de planta baja y principal, y se compone de varias habitaciones y tres patios grandes, así como también de un corral, talleres, almacenes para colocar obra, cuadras, cocheras, hornos, una cueva y una fuente que se surte con unos 2 rs. de agua, y un pozo en uno de los dos patios, con agua abundante aunque muy profundo.

Efectivamente, tal y como podemos ver en los dos planos que con mayor detalle describen la distribución de la Fábrica, custodiados en el AGP (AGP 4574 y 4575), el edificio se distribuía en torno a tres grandes patios, los dos más al norte procedentes del edificio de la Granjilla. El cuerpo sur y principal contenía, entre otras, las dependencias para descanso y aseo de los reyes, la oficina del director y el archivo, la portería, almacenes de porcelana y loza de primera clase, y en el piso superior las habitaciones para el administrador, oficial y operarios. El resto del edificio - prácticamente en su totalidad de una sola planta- estaba ocupado por la fábrica propiamente dicha y las distintas salas de talleres, hornos y maquinaria.

En lo que atañe a la producción ceramista de la manufactura, no nos

10 Suponiendo que el pie al que se refiere Madoz sea el pie castellano, que es lo más probable, la medida de la fachada norte sería de 117 metros y la de la oeste de 127 metros (1 pie castellano son 0,278635 metros). Comparándolo con las distintas mediciones que tenemos del parcelario urbano y que se parecen bastante entre sí, podemos ver que Madoz se aproxima mucho en uno de los lados del rectángulo (las fachadas norte y sur son prácticamente iguales), que mide según él 117 metros y en los planos 118 metros aproximadamente. Para el otro lado, en cambio, la dimensión de Madoz resulta bastante superior (129 metros frente a los algo menos de 115 metros que se pueden extraer de los levantamientos). 
detendremos en ello, al tratarse de un tema ampliamente estudiado. Solamente cabe mencionar que la Fábrica de Porcelana de La Moncloa tuvo tres etapas (Sánchez, 1989, Sierra y Tuda, 2000 y Fernández 2009), fue clausurada en 1850 y reinaugurada años más tarde por los hermanos Zuloaga (Rubio, 2005), aunque en realidad esta última etapa lo único que conservó de la Fábrica original fue el nombre, pues se trataba de una sociedad privada que se instaló en otros edificios en el parque del Oeste.

\section{LA LLEGADA DE LA ESGUELA GENERAL DE AGRICULTURA}

El antiguo edificio de la Fábrica (Figura 3) quedó en desuso durante casi veinte años, hasta que en 1865 el Real Sitio de La Florida y La Moncloa pasó a pertenecer al Estado ${ }^{11}$. En 1869, tras la Gloriosa, el gobierno provisional entregó la finca al Ministerio de Fomento, para instalar allí la Escuela de Agricultura ${ }^{12}$, que se trasladaba de esta manera desde su ubicación en Aranjuez (López, 1868, pp. 424-425) a Madrid ${ }^{13}$.

El deseo de una regularización de las enseñanzas agrícolas en España, con base científica y académica, venía de largo, desde finales del siglo XVIII, cuando la Sociedad Económica Matritense empezó a difundir estudios y charlas relacionados con el estado del campo español o los avances tecnológicos (Maldonado, 2004, pp. 181-182). Su situación geográfica respondía también a una necesidad que podríamos calificar casi de tipología arquitectónica: las escuelas de agricultura precisaban de edificios para las clases y amplios salones para las máquinas, pero también habían de rodearse de grandes extensiones de terreno que les permitieran llevar a cabo los estudios prácticos. Ya la Escuela de Aranjuez había funcionado de esta manera y ello volvía a repetirse en La Moncloa, con la ventaja de estar aún más cerca de la ciudad -La Florida formaba parte de la transición urbe-campo al noroeste de la capital-, lo que la hacía fácilmente accesible al alumnado.

En La Florida, los agrónomos se asentaron en los diversos edificios existentes. El Palacete de La Moncloa se ocupó con las dependencias administrativas y la

11 Esta cesión se produjo mediante la enajenación parcial de algunos bienes del Patrimonio Real, de los cuales el Estado se quedaba el $75 \%$ en calidad de ingresos públicos y el resto se reservaba para la reina Isabel II, hecho que suscitó numerosas críticas, entre ellas el conocido artículo de Emilio Castelar El rasgo, publicado el 25 de febrero de 1865 en el periódico La Democracia.

12 Por decreto de 28 de enero de 1869 se asignaban a la Escuela General de Agricultura (antes Escuela Central de Agricultura) los terrenos de La Moncloa que habían pertenecido al Patrimonio Real. La apertura oficial de la Escuela tuvo lugarel 15 de marzo de 1869 (Gaceta de Madrid, 4 de marzo de 1869,p. 1).

13 La Escuela Central de Agricultura de Aranjuez se había inaugurado en 1855 en la finca de La Flamenca, situada junto al camino de Toledo al suroeste del centro de la población. La Flamenca era también propiedad de la Corona, que la había cedido a los agrónomos dado el interés en establecer una enseñanza reglada de la agricultura en España. Sin embargo, las desavenencias políticas (Cartañà, 2005, p. 141) y los problemas económicos de la Escuela forzaron su traslado a un edificio más pequeño en el centro de Aranjuez en 1863. Fue finalmente clausurada en 1868 (Muñoz, 2017). 


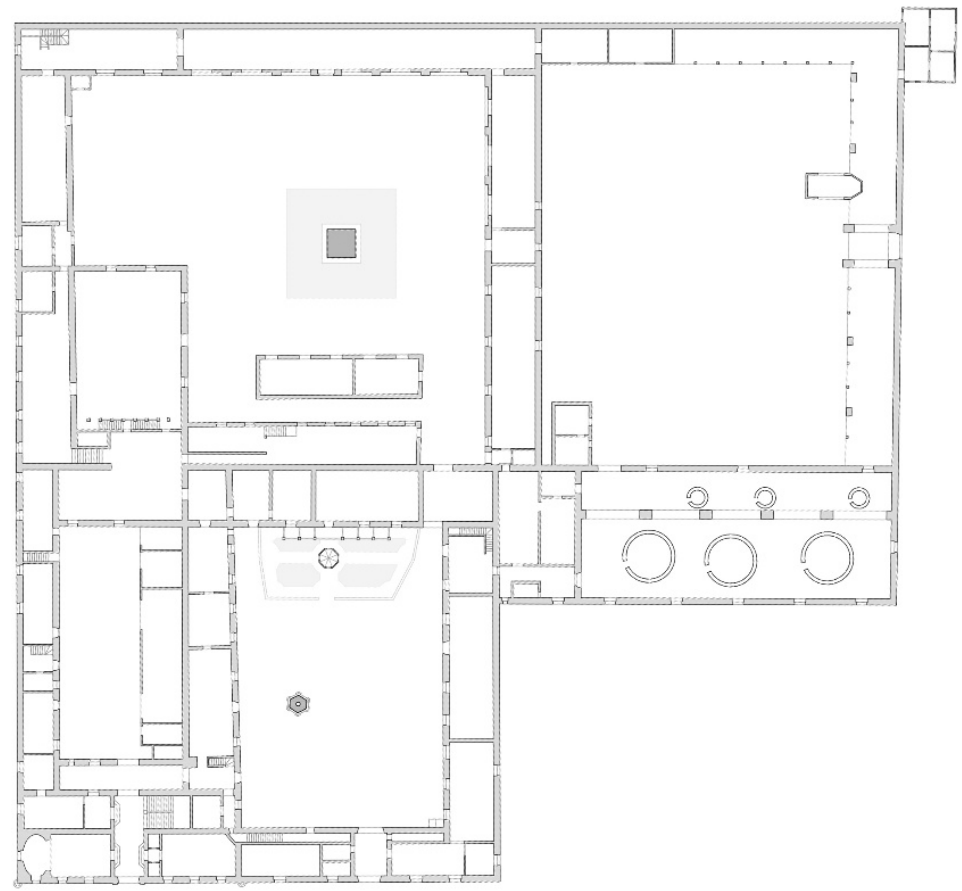

Figura 3. Planta de la Fábrica de Porcelana hacia 1870 (elaboración propia)

vivienda del director; la casa de oficios con cocinas, lavandería y otras instalaciones, y con los dormitorios para estudiantes -ya en La Flamenca había alumnos en régimen de alojamiento por diversos motivos, en un primitivo ejemplo de lo que más tarde serían las residencias de estudiantes-. Las aulas y cátedras se instalaron en la Fábrica de Porcelana, al igual que el primer Museo Agronómico. En 1876, la institución pasó a llamarse Escuela Superior de Ingenieros Agrónomos. Durante estos primeros años y hasta 1880 se fue extendiendo por La Moncloa, estableciendo huertas, campos de prácticas, pastos y cultivos y construyendo multitud de pabellones, especialmente en el entorno del Palacete de La Moncloa. La Granja de Castilla la Nueva se incorporó también al complejo, que en esos años pasó a llamarse Instituto Agrícola de Alfonso XII, nombre que mantuvo hasta la Segunda República ${ }^{14}$.

14 Apoyada por la monarquía restaurada, la institución se convierte en Instituto Agrícola de Alfonso XII por Real Orden de 12 de julio de 1881 (Gaceta de Madrid, 17 de julio de 1881, p. 162). Por Orden de 29 de abril de 1931 el conjunto pasó a llamarse Instituto Nacional Agronómico (Gaceta de Madrid, 1 de mayo de 1931, pp. 469-470). 


\subsection{Transformaciones en el edificio de la Fábrica de Porcelana}

De las reformas que se hicieron en la Fábrica de Loza para albergar la Escuela hemos hallado poca documentación de carácter general, aunque sí varios proyectos parciales. Es posible que, en la mayoría de los casos, dadas las muchas obras que se tuvieron que acometer en el resto de edificios (Cartañà, 2005, p. 125), aquí se tratara simplemente de eliminar hornos y maquinaria para adecuar los espacios a su nuevo uso. Parece probable que en un primer momento se procediera a ocupar la Fábrica con una mínima intervención, pues los proyectos encontrados datan de 1880 en adelante.

Sí tenemos constancia de un proyecto del año 1880 (AGA 31/8131) para dividir la original sala de hornos en dos estancias. Se trataba de una gran habitación que cerraba el patio este por el sur -tenía, por tanto, su fachada exterior al sur y la que daba al patio miraba al norte-. Este proyecto la divide mediante un muro que seguía la línea de pilares existente en el centro de la estancia; el espacio mayor, que era también el exterior, se destinó a salón de máquinas y el menor a almacén. La nueva galería de máquinas puede apreciarse en un grabado publicado en La Ilustración Española y Americana en 1880 (n. 41, p. 269), con motivo de su inauguración por el rey Alfonso XII.

Un proyecto de mayor alcance es el de 1885, para una nueva vivienda para el guarda y salas de maquinaria (AGA 31/8133). En esta propuesta, que fue llevada a cabo, tal y como puede verse en planos de La Moncloa de años posteriores, se sustituían el "espacio ocupado hoy por los cobertizos, gallineros, casa del guarda y corrales de la casa de la china situados en el ángulo N. E. del Instituto Agrícola de Alfonso XII"15. Estas crujías eran hasta entonces porches abiertos al patio. La vivienda del guarda se situaba en la esquina nordeste del edificio y sustituía a la previa, de menor tamaño. En los planos de este proyecto, firmados por el arquitecto Lorenzo Álvarez y Capra, desafortunadamente se ve solo parte del resto del edificio, pero sí puede apreciarse que la sala de hornos de la manufactura está ya dividida por un muro, con lo que podemos concluir que el primer proyecto al que nos referíamos más arriba también se había ejecutado (Figura 4). Desde el punto de vista técnico,

el sistema de construcción de estas salas consiste en muros de fábrica de ladrillo al descubierto, reforzados por contrafuertes del mismo material a la distancia de $4 \mathrm{~m}$ entre ejes y coronados por medio de una cornisa general también de ladrillo al descubierto, dejando entre cada dos contrafuertes ventanas de $1,9 \mathrm{~m}$ por $1,2 \mathrm{~m}$ de altura y tres puertas situadas en los testeros de las alas (AHN FC-M $\left.{ }_{-}^{\circ} \mathrm{O}_{-} \mathrm{P}, 91\right)$.

15 Aunque este proyecto se encuentra en el AGA, la documentación de su revisión por parte de la Junta de Obras se halla en el Archivo Histórico Nacional (en adelante AHN), bajo la signatura AHN FC-M ${ }^{\circ}$ O_P,91. 


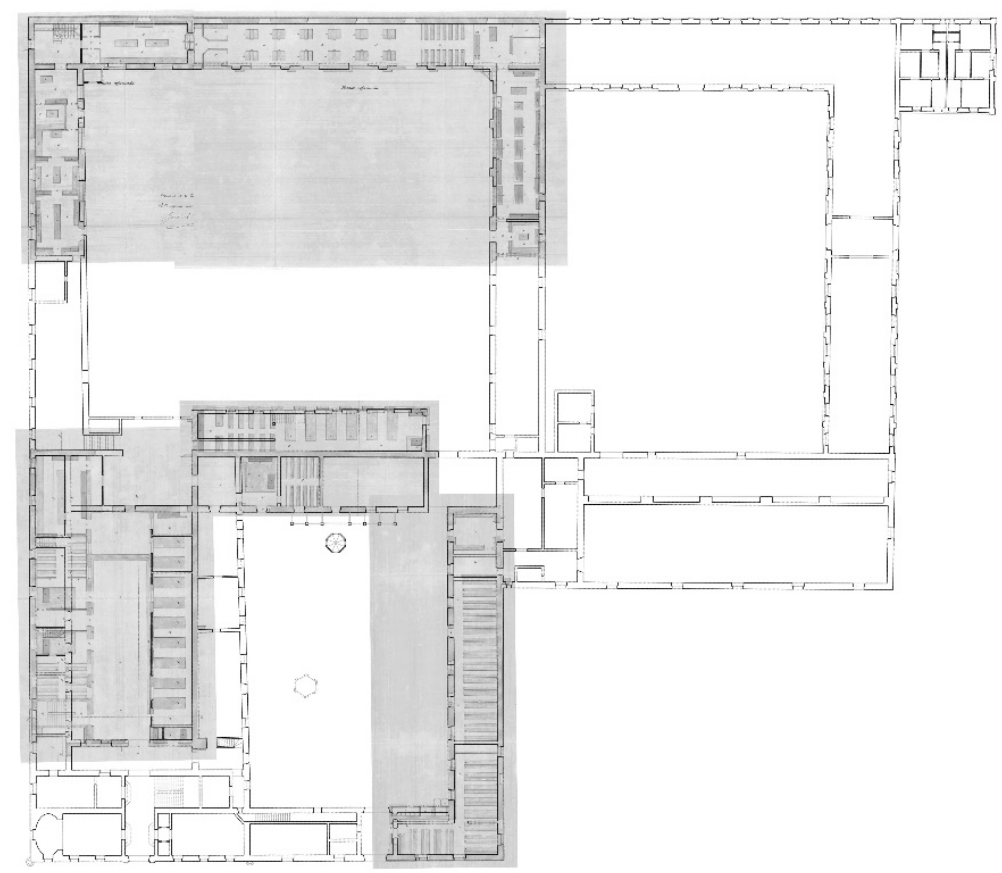

Figura 4. Planta de la Escuela de Agrónomos hacia 1890 (elaboración propia)

En 1887 se desarrolla otro proyecto más, esta vez en torno a los patios del oeste (AGA 31/08132). Los planos de este proyecto están firmados por José de Arce -importante figura en el mundo agronómico y entonces director de la Escuela- y resultan sumamente interesantes, puesto que reflejan el estado del edificio en aquel momento. Son encuadres parciales de diferentes zonas del edificio, que se han unido en un dibujo para tener una visión global de las reformas que se proponían (Figura 4). La mayoría de las actuaciones se refieren a aulas y talleres, aunque también hay espacios para el descanso de los estudiantes. Analizando esta documentación podemos ver cómo, efectivamente, en esta zona se habían hecho pocas reformas con respecto a los últimos datos que tenemos de la Fábrica de Porcelana, y cómo este proyecto proponía por fin afrontar la modernización y adecuación de las instalaciones, además de subsanar los diferentes problemas que el edificio presentaba. Sin embargo, parece que al menos una parte de las modificaciones propuestas por Arce no se llevaron a cabo. Como ejemplo, el agrónomo proponía abrir huecos en la fachada norte del edificio, y en una de las escasas fotografías que se conservan del mismo, fechada hacia 1925, ese frente sigue siendo ciego. 
También existe testimonio fotográfico de cómo se ocuparon antiguas salas de la Casa de la China, como el salón oval, que en su momento había sido sala de reposo de los reyes y que después fue transformado en aula (Figura 5). Las aulas y cátedras se establecieron en las estancias más nobles de la Fábrica de Porcelana, concentradas en el cuerpo principal al sur, mientras que las crujías más bajas, alrededor de los patios, se ocuparon con talleres, laboratorios, exposiciones, salas de máquinas agrícolas y almacenes de aperos.

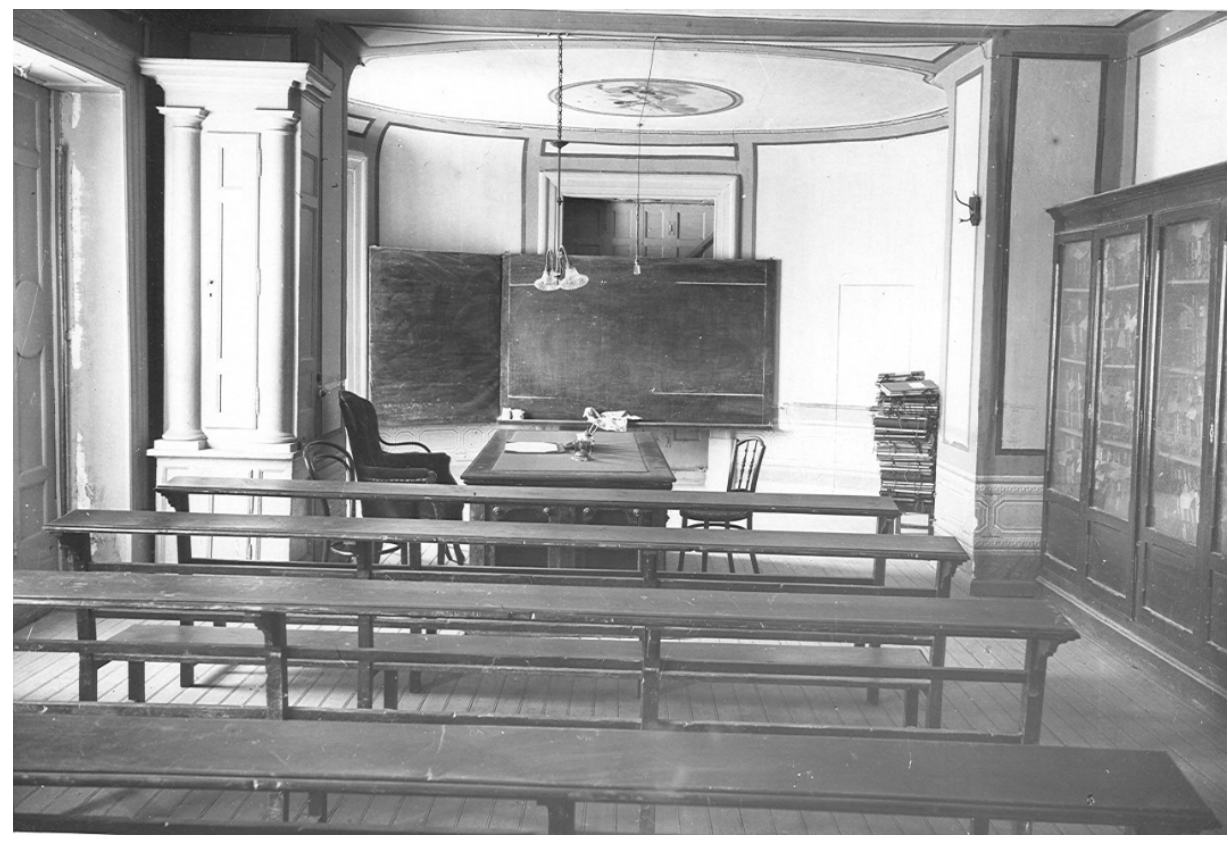

Figura 5. Aula en la Escuela de Agrónomos. ETSIAAB. UPM

Durante los años siguientes a su llegada, los agrónomos fueron colonizando con cultivos y tierras de labor la finca de La Florida, si bien estas explotaciones se concentraban fundamentalmente en tres zonas: en el entorno del Palacete de La Moncloa y la Granja de Castilla de la Nueva, alrededor de la Fábrica de Porcelana y en toda la zona oeste de la finca -que era la más próxima al río-, junto a los viveros.

En diversos planos dibujados desde 1880 y en adelante puede observarse cómo el entorno de la Fábrica de Porcelana va rodeándose de huertas. En un pequeño plano de la zona contenido en una memoria que redacta Alonso Martínez (1911, p. 39), a la sazón director de la Escuela en 1911, aparecen ya descritas las funciones de estas plantaciones e instalaciones varias: campos de riegos, huertas, viñedos, olivar, jardín botánico, la estación meteorológica al norte de la escuela o la nueva estación de ensayo de máquinas al oeste (Arce, 1911, pp. 13-15), que desaparecería con la 
construcción de la Avenida de Alfonso XIII, actual carretera de La Coruña, y el Viaducto de los Quince Ojos a partir de 1930.

Además de paisajísticamente, también la zona empezó a evolucionar en cuanto a infraestructuras de transporte: hacia 1880 comenzó a funcionar un tranvía de tracción animal que circulaba desde la plaza de La Moncloa hasta la Escuela de Agricultura ${ }^{16}$; este tramo se convirtió en 1905 en prolongación de la línea 22, que partía de Embajadores y pasaba por la Puerta del Sol (López, 1986, p. 88). Más tarde, en 1916, se inauguró la línea 41, que unía Santo Domingo con el Club Puerta de Hierro, discurriendo por La Moncloa y la Escuela de Agrónomos, en cuyo jardín delantero se construyó una raqueta para los tranvías con remolque y desde donde partía una vía única que, salvando la fuerte pendiente del arroyo Cantarranas, cruzaba la vaguada y pasaba junto al Palacete de La Moncloa; posteriormente, ya con doble vía, atravesaba la Granja de Castilla la Nueva -cuyos grandes gallineros se podían ver desde el tranvía-, y proseguía hacia el norte cruzando el arroyo de las Damas y bordeando el estanque del mismo nombre, hasta llegar al monte de El Pardo (López, 1986, pp. 99-100; González, 2009, pp. 15-16). Y aunque no pasaba exactamente por la escuela, desde 1902 circulaba también un tranvía de vapor que conectaba San Antonio de La Florida con El Pardo, siguiendo un recorrido de 11 kilómetros muy pintoresco que discurría por los viveros, la Puerta de Hierro y la Fuente de la Reina (López, 1986, p. 61).

Esta dinamización del transporte vino de la mano de la aparición en la finca de nuevas instituciones que comenzaron a instalarse desde los últimos años del siglo XIX: el Campo de Tiro Nacional, el Asilo de Santa Cristina, el Casino Parisiana, el Instituto Rubio y el Instituto Ramón y Cajal, más adelante llamado Instituto de Higiene.

\subsection{Un nuevo edificio para la Escuela y su convivencia con el anterior}

En cuanto a la Fábrica de Loza, las puntuales reformas efectuadas por la Escuela no fueron capaces de detener su deterioro, con lo que ya "en 1908 se acordó la construcción del nuevo edificio para albergar la Escuela de Ingenieros Agrónomos, por considerar en estado ruinoso la existente" ${ }^{17}$. No debió de ser el primer intento por construir un nuevo edificio para la Escuela, pues se encuentra en el AGP un alzado con una propuesta de Enrique Repullés Segarra para una Escuela de Ingenieros

16 Esta línea figura con un trazado más largo, que llega hasta el Palacete de La Moncloa, en un plano de La Moncloa conservado en el Servicio Geográfico del Ejército, que debe de estar dibujado hacia finales del siglo XIX. López Bustos también es consciente de este documento, que tal vez refleje un proyecto de ampliación, aunque, tal y como él cuenta, esta línea de tranvía fue "rápidamente construida, circuló con tracción animal durante algunos años y luego quedó abandonada" (López, 1986, p. 88).

17 Informe del director de la Escuela, Excmo. Sr. D. Ignacio Víctor Clario Soulán, al Excmo. Sr. Subsecretario del Ministerio de Fomento, 1 de marzo de 1924. ETSIAAB. UPM. 
Agrónomos del año 1888 (AGP P4824). De este proyecto no se sabe mucho más, ni siquiera si su ubicación era también La Florida y el proyecto de Repullés venía a ser una primera alternativa para sustituir a la Fábrica de Porcelana. Tanto la localización en ese momento de la Escuela, como el entorno natural, con montañas al fondo, que rodea al edificio en el dibujo, apoyan esta idea.

El proyecto que finalmente se realizó fue el planteado, alrededor de 1915, por el arquitecto madrileño Carlos Gato Soldevila ${ }^{18}$. Si tomamos en consideración las fechas en las que están firmados los planos, el proceso de diseño debió de ser lento, como ocurriría más adelante con la ejecución de la obra. Así, las plantas datan de 1912, pero la sección está firmada en 1916 y los alzados en el año 1922.

Se inauguró -aunque solo estaba parcialmente construido- en $1925^{19}$. Estilísticamente era un edificio de apariencia decimonónica, en un estilo francés muy de moda a finales del XIX, y similar a edificios cercanos de la misma época, como el Instituto Nacional de Higiene, que desapareció en la guerra civil. Era una obra de piedra y ladrillo, en la que se jugaba precisamente con el contraste entre la fábrica de ladrillo visto de dos colores - uno rojizo y el otro verdoso-, los cajones de mampostería y la piedra de tono claro de los órdenes de columnas, frisos, cornisas y frontones (Muñoz, 2018, p. 121). Las sucesiones de pilastras, en esquinas y accesos, y la ornamentación desempeñaban un papel compositivo fundamental, pero con un peso algo excesivo. Precisamente la decoración, bastante en la línea de lo que solía proponer Gato, aunque tal vez más abundante en este proyecto, fue uno de los principales motivos de críticas negativas que recibió el edificio.

En planta estaba compuesto por tres cuerpos de dos alturas, uno principal y dos alas laterales perpendiculares a él en sus extremos, abrazando una plaza abierta de acceso, orientada al sur, que se proyectó ajardinada. Los encuentros entre dichos cuerpos se remataban con dos plantas más, al igual que el final de los brazos laterales y el centro del volumen principal, de modo que puede entenderse como cinco pabellones principales conectados entre sí mediante volúmenes longitudinales de carácter secundario. En el centro de las alas laterales sobresalían unos pequeños cuerpos transversales que contenían accesos secundarios en el frente que daba a la plaza, y estaban rematados en forma absidial en su parte posterior. La estructura formal de este edificio es, en realidad, muy sencilla y ordenada (Figura 6). Así, este mismo criterio de señalar el centro de las alas laterales se seguía en el cuerpo principal, solo que, al ser este más importante, también adquirían mayor relevancia

18 Gato Soldevila -o Soldevilla, aunque aquí hemos preferido usar la forma con la que firma él sus proyectos- era profesor de la Escuela de Arquitectura y arquitecto del Ministerio de Fomento, puesto por el que posiblemente se le encargase la construcción de la Escuela. Hemos encontrado copia del proyecto de Gato conservada en el AGA (AGA 31-04864).

19 La inauguración se hizo coincidir con la festividad del patrón de los agrónomos, san Isidro Labrador, el día 15 de mayo. ABC, 16 de mayo de 1925, pp. 11-12. 
el volumen transversal y el ábside, que se convertían en el quinto pabellón y acceso principal al edificio.

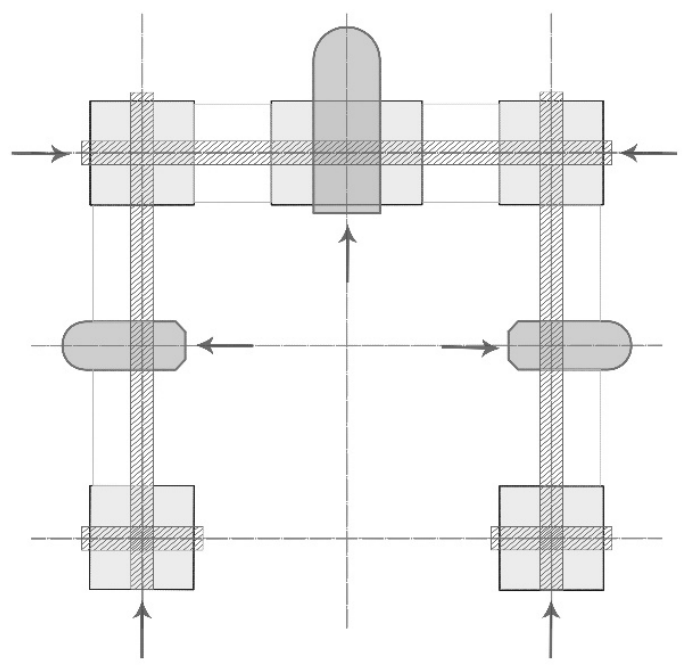

Figura 6. Esquema analítico del edificio de Gato Soldevila (elaboración propia)

Respecto a la distribución interior que proponía el proyecto, en la planta noble se situaban los gabinetes y cátedras de las distintas asignaturas, la biblioteca y el salón de actos, que ocupaba el ábside en el centro del edificio. Este espacio se iluminaba cenitalmente mediante un lucernario que permitía el paso de la luz natural, al igual que ocurría en las salas situadas en las alas laterales del edificio y en el vestíbulo del acceso principal, al que Gato denomina en sus planos "Gran Patio", puesto que en realidad se trataba del patio interior del pabellón central, que se cubría con vidrio en la planta baja. A través de este espacio, se iluminaba el vestíbulo equivalente en el sótano, donde se hallaban el comedor, el museo de máquinas, la estación agronómica, talleres y cuartos de instalaciones. Los cuatro pabellones que remataban los extremos del edificio albergaban las distintas dependencias de las estaciones, las cátedras y gabinetes de profesores, así como los aseos. Los cuatro niveles de estos pabellones estaban comunicados mediante escaleras secundarias, que también se iluminaban con lucernarios.

Del mismo modo que ocurría con el edificio de la Fábrica de Loza, la nueva escuela aprovechaba la caída del terreno hacia el Cantarranas en su parte posterior; por ello, la fachada principal tenía una altura menos que la posterior, puesto que la cota del patio principal era unos metros más alta. De esta manera, los huecos de semisótano de la fachada sur eran huecos completos en la norte, con lo que la planta sótano, en realidad, era una planta baja en la fachada trasera: "El terreno queda por el lado del patio a nivel con la carretera y por la parte exterior queda más bajo para 
que la planta resulte a nivel" ${ }^{10}$. Este desnivel del terreno se salvaba mediante sendas escaleras adosadas en las fachadas laterales (Muñoz, 2018, pp. 121-122).

El nuevo edificio se situó sobre el de la antigua Fábrica. Aunque la ubicación exacta de la Casa de la China no sea posible conocerla con absoluta precisión, sí podemos aproximarnos bastante, dadas las particulares condiciones de construcción del edificio nuevo. Por ejemplo, existe una fotografía que nos permite asegurar que los frentes traseros de ambos edificios eran coincidentes ${ }^{21}$.

Su construcción fue muy lenta; el proyecto de Gato está firmado en 1912, pero

hasta fines de 1923 no se ha terminado la mayor parte de un cuerpo de los tres de que consta el nuevo edificio y se ha anunciado en la Gaceta la subasta para la terminación de la totalidad de las obras. En estos momentos, el edificio que diecisiete años atrás se consideró en estado ruinosos (sic), continúa utilizándose para la enseñanza con grave peligro para la vida de profesores y alumnos: se ha derrumbado el techo de dos clases, parte del Museo de Máquinas y está próximo a desplomarse el resto, como puede verse por las fotografías que se acompañan...22.

Efectivamente, la docencia continuó en la Fábrica de Porcelana mientras se construía el nuevo edificio ${ }^{23}$; se comenzó a levantar el ala este, de tal forma que no hiciera falta demoler totalmente el antiguo edificio de la manufactura y pudiera seguir en $\mathrm{uso}^{24}$, aunque las condiciones fueran considerablemente precarias. De hecho, la inauguración del nuevo edificio tuvo lugar el 15 de mayo de 1925, evento al que asistió Alfonso XIII, pero fue en realidad inauguración tan solo del cuerpo este del mismo, que era el que se hallaba concluido en aquel momento.

Terminado el primer cuerpo, las clases y la actividad académica se trasladaron parcialmente allí, y se demolió la Fábrica de Porcelana ${ }^{25}$ paulatinamente, a medida que proseguía la construcción del edificio. Sin embargo, los problemas económicos

20 Proyecto de Escuela Especial de Ingenieros Agrónomos. Pliego de condiciones facultativas y económicas. Ca. 1924. AGA, 31-04864.

21 Fotografía tomada hacia 1925. ETSIAAB. UPM.

22 Informe del director de la Escuela. 1924. ETSIAAB. UPM.

23 De la lentitud de las obras dan fe los diversos escritos e informes explicando los aumentos de presupuesto con respecto al proyecto inicial. Así, en 1921 se estima que el presupuesto inicial de 1914 habría aumentado en aproximadamente 1.200 .000 pesetas (el debate fue mucho más amplio, pero aquí no nos detendremos en ello). AHNOB SOLDEVILLA_C_0001_D_0001, 1-13.

24 Existe un plano de Madrid de alrededor de 1915 (Nuevo plano y callejero de cobranzas de Madrid. Centro Geográfico del Ejército), en el que aparecen dibujadas a la vez la Fábrica y el ala este del nuevo edificio. El dibujo tiene poco detalle y no es particularmente fino (por ejemplo, es claro que no conoce bien el proyecto de Gato), pero da testimonio de la coexistencia. En mi opinión, hubo de demolerse una pequeña parte del este del edificio antiguo, con seguridad la casa de guardas y probablemente toda la fachada del patio este.

25 Posiblemente el cuerpo sur y principal de la manufactura fuera lo último en tirarse, ya que era la zona menos afectada por las obras y seguramente, dada la mayor calidad de su construcción, la que se encontrara en mejores condiciones. 
volvieron a paralizar la obra una vez acabado el cuerpo principal y cuando faltaba por terminar el brazo oeste, que quedó interrumpido a la mitad. La U que debía formar el edificio proyectado no llegó, por tanto, a completarse.

Con la construcción de la nueva escuela termina también la vida del edificio de la Fábrica de Porcelana. La siguiente composición (Figura 7) muestra una hipótesis de la evolución que experimentó la Casa de la China desde la instalación de la Escuela de Agrónomos dentro de sus muros:
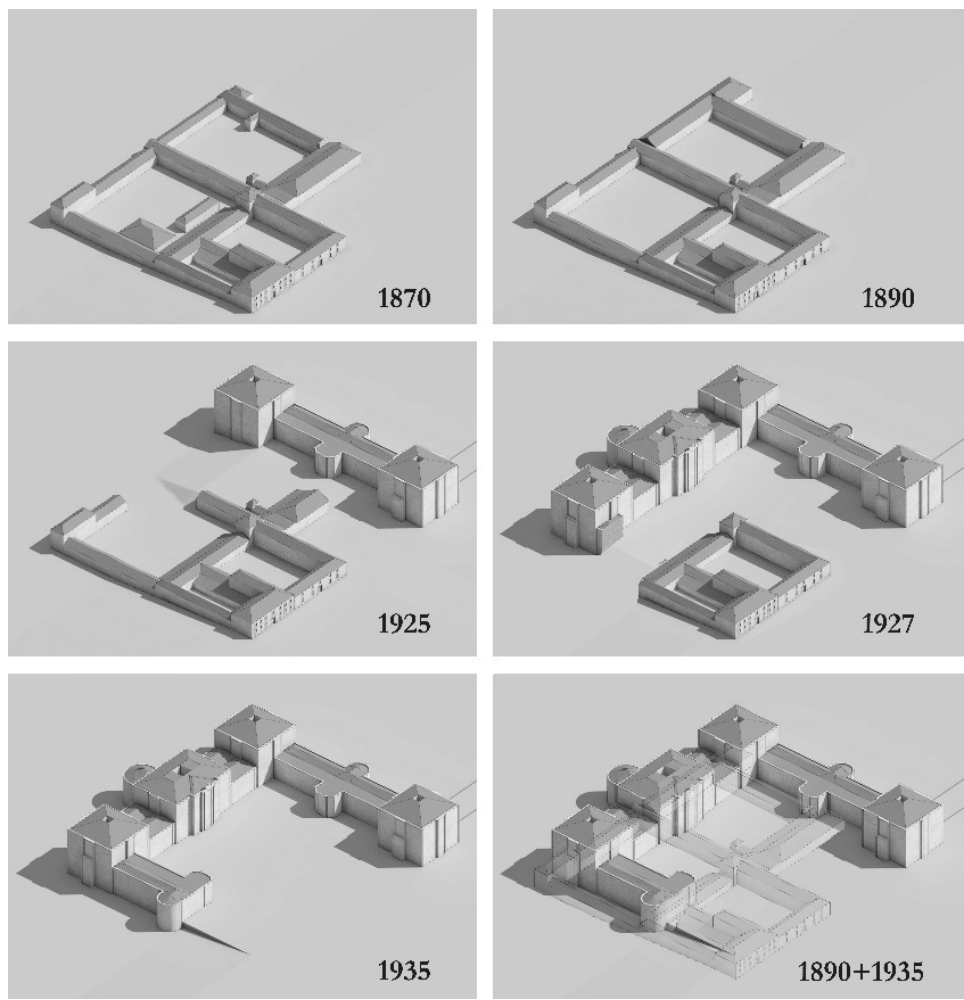

Figura 7. Fábrica de Porcelana y Escuela de Agrónomos en 1870, 1890, 1925, 1927 y 1935 (elaboración propia)

En 1935 encontramos otro proyecto, ya no firmado por Carlos Gato -que había muerto en Suiza el 1 de julio de $1933^{26}$, sino por Emiliano Castro. Este proponía terminar el ala oeste del edificio siguiendo el proyecto original y cerraba el patio resultante entre los dos brazos con una verja de forja. Sin embargo, tal proyecto nunca se llevó a cabo y al comienzo de la guerra civil el edificio no estaba concluido, aunque sí en pleno funcionamiento. La simetría que actualmente presenta el edificio se debe a la reconstrucción posbélica.

26 Boletín Oficial de la Provincia de Madrid, 11 de octubre de 1933, p. 5. 
El proyecto de Castro resulta muy interesante de estudiar, puesto que se realiza a partir de la Escuela ya construida -aunque, al ser parcial, los planos detallan solamente un área del edificio-. Se convierte así en una especie de proyecto as built, que al compararlo con los planos de Gato nos permite ver qué fue lo que se ejecutó en realidad.

\section{LA ESCUELA DE INGENIEROS AGRÓNOMOS EN LA GIUDAD UNIVERSITARIA}

Unos años antes de este proyecto de ampliación, la Escuela se había visto inmersa dentro de otro de mucha mayor ambición y alcance: el de la Ciudad Universitaria. Tras diversos intentos y proyectos parciales, el 17 de mayo de $1927^{27}$ se constituyó la Junta Constructora de la Ciudad Universitaria, y se nombró como arquitecto director a Modesto López Otero (Chías, 1986, pp. 37-43). No es objeto de este artículo el interesante proceso de diseño del que sería el primer campus de Madrid (González y Ortega, 2018, pp. 86-93), pero sí consideraremos a modo de cierre la manera en que se incluyó el complejo de agrónomos, y más concretamente el edificio de la Escuela, dentro del nuevo conjunto universitario.

Una vez decidido el emplazamiento de la Ciudad Universitaria en La Moncloa, la principal necesidad era aumentar y regularizar los terrenos del futuro campus. Evidentemente, esta ampliación afectaba a la Escuela de Agrónomos, puesto que ocupaba gran parte de los terrenos de La Florida. Esto fue aún más claro cuando se planteó también dedicar una sección del campus a las Bellas Artes, que se situarían al otro lado de la nueva carretera de La Coruña, en la zona oeste de la finca, y sobre algunos de los campos de prácticas de la Escuela de Agrónomos, aunque varios de ellos habían sido ya suprimidos al construirse la Casa de Velázquez en 1920.

Así comenzaron las obras, que se extendieron por la totalidad de La Moncloa, y, tal y como señala Pilar Chías (1986, p. 20), "el proyecto se situó indiscriminadamente sobre solares o cerros desnudos, pero también sobre tierras de labor, cultivos y granjas explotados por el Instituto Agrícola Alfonso XII, y sobre jardines y praderas utilizados asiduamente como parque público". La finalidad era obtener una plataforma de rasante única sobre la que ubicar las facultades del conjunto universitario. Tanto el proyecto como las obras suscitaron gran controversia en la prensa del momento, que opinaba que Madrid perdía de esta manera uno de sus parques públicos más populares ${ }^{28}$. Todos estos artículos más o menos acalorados hay que entenderlos y contextualizarlos en el medio del que proceden; es verdad que el proyecto de la Ciudad Universitaria no fue tan respetuoso con su entorno como podría haberlo sido (González y Muñoz, 2020,

27 Real Decreto de creación de la Junta Constructora de la Ciudad Universitaria. Gaceta de Madrid, 17 de mayo de 1927, pp. 1081-1083.

28 "Hay que defender La Moncloa", La Voz, 3 de octubre de 1924, p. 2; o "Madrid pierde una zona verde", El Socialista, 12 de septiembre de 1929, p. 1. 
pp. 886-889), pero no es menos cierto que La Florida no era el frondoso y fresco vergel del que algunos de estos escritos hablaban. No hay que pasar tampoco por alto que había también una voluntad política en la elección de La Moncloa como ubicación del campus, apoyada por los círculos más próximos al rey. Alfonso XIII buscaba al impulsar este proyecto, además de celebrar el vigesimoquinto aniversario de su coronación -que era la versión oficial- (Rodríguez-López, 2015, p. 17), ganar protagonismo frente a la cada vez más fuerte figura política del momento, la del general Primo de Rivera (Pérez-Villanueva, 2018, pp. 28-31).

A pesar de tantas alteraciones no menores, se respetaron también muchas de las edificaciones existentes y parte de la red viaria, bien por imposibilidad de su traslado, como era el caso del Asilo de Santa Cristina, bien porque cumplían una función que interesaba mantener, como ocurría con la Escuela de Agrónomos, que, además de ser una institución muy consolidada, tenía clara relación con el carácter universitario e investigador que se quería infundir a la zona. En este sentido, la situación céntrica dentro de la finca de la Escuela de Agrónomos forzó en cierta medida la estructura urbanística del proyecto. El eje principal de la Ciudad Universitaria, rematado por el Paraninfo, parte del fin del paseo de la Moncloa en su encuentro con la Escuela (González y Muñoz, 2018, p. 365). La existencia del edificio de Agrónomos y de la vía rodada, que contaba, además, con toda una infraestructura de tranvía, marcó el punto más adecuado para el arranque del eje principal del campus, que se situó de esta manera entre la Escuela y el Asilo de Santa Cristina.

Por otro lado, en el esquema de vías de circulación de 1929 (AGUCM, Ciudad Universitaria) se puede apreciar un esbozo de la estructura del futuro campus, en el que el eje central arranca aproximadamente en el punto que acabamos de indicar, para seguir una clara dirección norte-sur. Sin embargo, la avenida Complutense no está perfectamente orientada al norte, sino ligeramente inclinada hacia el noroeste y casi en paralelo con la Escuela de Agrónomos. Así que todos los indicios que parecieran apuntar a una voluntad de incorporar el antiguo edificio de Agrónomos al conjunto, quedan diluidos con ese "casi" paralelismo. En efecto, tal y como se advierte en la imagen (Figura 8), al superponer el eje vertical de la Escuela de Agrónomos con el del campus, se observa que, si bien por poco, no son coincidentes. Esta cuestión podría estar relacionada con un error durante los replanteos de las obras de construcción, pero hay planos del campus que disuaden pronto de esta idea: en ellos puede ya apreciarse que ese leve giro no es lo suficiente como para ajustarse a los ejes marcados por los edificios existentes de Agrónomos. Se perdía así la oportunidad -absolutamente viable en este caso- de integrar la avenida de la Universidad y, por extensión, el resto del campus, que se organiza siguiendo el eje marcado por la vía, con los edificios de Agrónomos, aunque formalmente fueran arquitecturas alejadas del nuevo proyecto. No disponemos de los procesos de diseño completos de la Ciudad Universitaria, que podrían arrojar más luz sobre este asunto, pero parece claro que el proyecto del campus se planteó de un modo bastante ajeno 
a lo que lo rodeaba, y la Escuela de Agrónomos quedó así al margen del nuevo complejo.

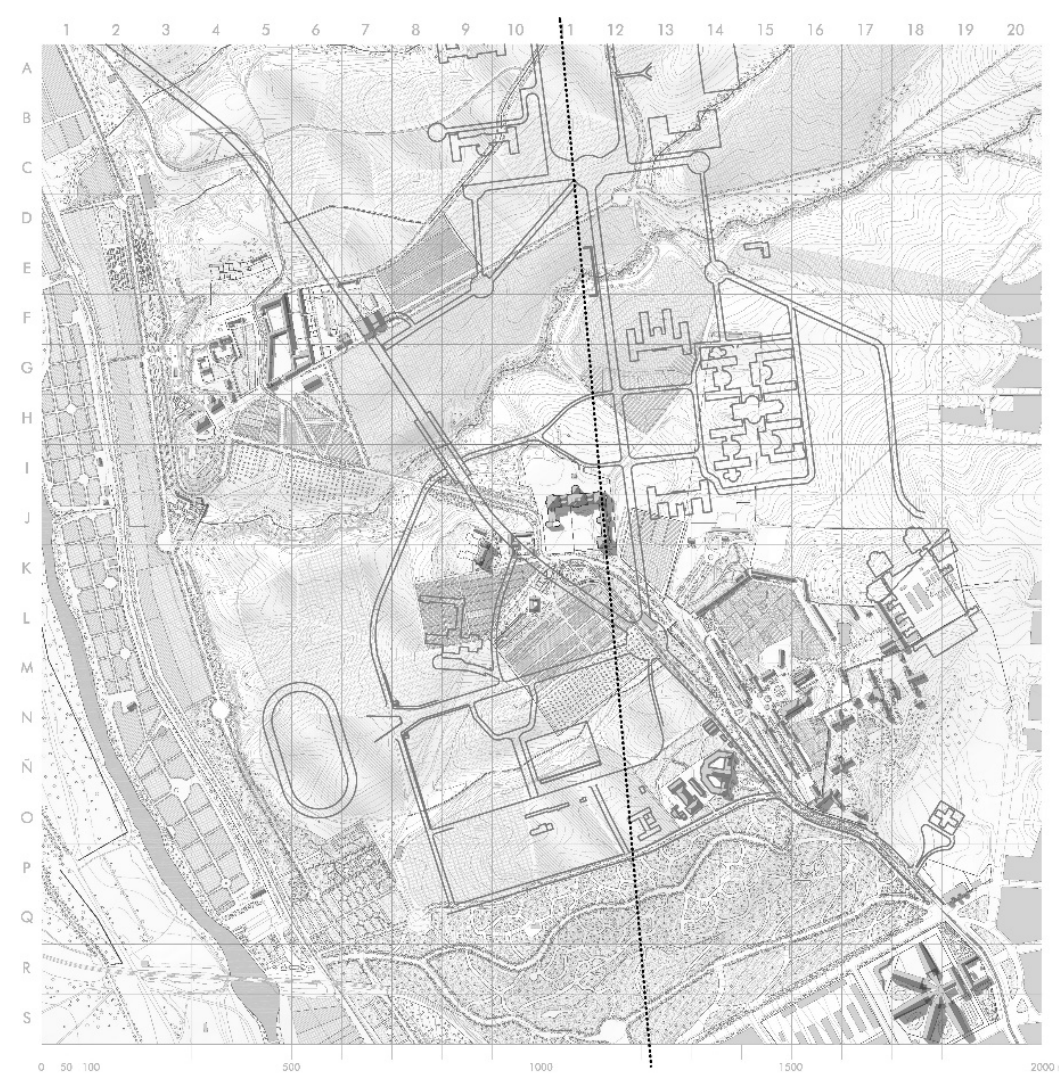

Figura 8. Plano de La Moncloa en 1927. Se superpone el proyecto de la Ciudad Universitaria y el eje de la Escuela de Agrónomos (elaboración propia)

Más allá de las relaciones que puedan establecerse con el proyecto del campus, la llegada de la Ciudad Universitaria afectó considerablemente a la Escuela de Agrónomos, puesto que ocupaba gran parte de los terrenos de La Florida. Con la construcción de la nueva universidad, la Escuela perdía una superficie muy importante de sus campos de prácticas (Losada et al. 2006, p. 14 y Muñoz 2018, pp. 132-133), que fueron reduciéndose progresivamente para dar cabida a las distintas facultades, "hasta límites que pronto fueron insuficientes para cumplir el cometido que tenían asignado" (Escuela 1980, p. 12). Lo que llegó a construirse antes de la guerra supuso la pérdida de huertas al levantarse la Escuela de Arquitectura -otras se habían eliminado al edificar la Casa de Velázquez-; de los jardines frente a la Escuela; del campo de riegos, que se desmanteló al haber quedado una gran parte 
de sus terrenos ocupada por el grupo médico y la avenida de la Universidad; de un sector del olivar junto al Jardín Botánico Agrícola, que desapareció al rellenar el arroyo del Degollado para construir los campos de deportes; y de algunas tierras de labor y pasto de la Granja que estaban en la zona que ahora ocupaba la Facultad de Filosofía y Letras.

La convivencia entre la Ciudad Universitaria y el Instituto Agrícola parecía, no obstante, posible. En septiembre de 1934, se autoriza al director de la Estación Pecuaria Central a que el ganado lanar aproveche los pastos situados cerca de los campos de deportes. Por lo que se deduce del intercambio de información, se permitía el aprovechamiento de los campos que, según el decreto de 1928, ya pertenecían a la Ciudad Universitaria, mientras la Junta Constructora no les buscara un nuevo uso, manteniendo ese privilegio sobre otros ganaderos o agricultores interesados. Por su parte, el profesorado de la Escuela de Agrónomos se ofreció a realizar el proyecto de ajardinamiento de toda el área del campus.

El impacto que produjo la Ciudad Universitaria sobre el Instituto Agrícola de Alfonso XII se reflejó en los campos de prácticas y de labor, de los que se perdió bastante superficie, pero no así en los edificios, que fueron respetados por el proyecto. Sin embargo, las grandes obras civiles que se coordinaron en el tiempo con la construcción del campus sí tuvieron consecuencias sobre algunos edificios, que debieron ser demolidos y reubicados en otros puntos de la finca.

En torno a 1930 comenzó a construirse la nueva salida norte de Madrid. Esta había de ser una vía de primer orden y, por tanto, de un ancho mucho mayor que la antigua carretera -que transcurría paralela al Manzanares- y, desde luego, que las que cruzaban La Florida, que en la mayoría de los casos no pasaban de ser caminos arbolados. Esta nueva vía se planteaba como una vía-parque para unir la plaza de La Moncloa con la Puerta de Hierro, cruzando el campus, y de este modo evitar la construcción de viviendas de baja calidad -muchas veces autoconstruidas-, como ocurría en otras entradas a Madrid (Moya 2008, p. 93).

Aunque, en general, se mantuvo el trazado del antiguo camino de La Moncloa, sobre todo en el tramo frente al Asilo de Santa Cristina, al llegar a la Escuela de Agrónomos giraba y proseguía en una larga recta cruzando la vaguada del Cantarranas y dejando la Granja Modelo a la izquierda. De esta forma, no afectaba a las edificaciones principales de la Granja y transcurría por zonas de menor pendiente. Incluso así, hubo varios edificios que resultaron demolidos con esta operación.

El más relevante de todos ellos fue la Estación de Ensayo de Máquinas que había planificado José de Arce. Para que la carretera pudiera pasar entre la Escuela de Agrónomos y la Casa de Velázquez, se necesitaba más espacio que el que existía en ese momento, y por ello se derribaron las construcciones que había entre los dos edificios, que eran las que formaban el conjunto de la Estación de Ensayo de Máquinas, por en medio del cual pasaba justamente el trazado de la carretera. Este 
fue el motivo por el que Carlos Gato proyectó una nueva estación, que se construyó al norte de la Escuela de Agrónomos.

Esta situación quedaría congelada al estallar la guerra civil, que asoló el campus y fue especialmente dañina con algunos de sus edificios (Muñoz y González, 2019a y 2019b), como la Escuela de Agrónomos. Su destrucción y reconstrucción merecen un estudio detallado que se desarrollará en otra ocasión.

\section{GONCLUSIONES}

Al calor de los movimientos ilustrados de los siglos XVIII y XIX, la educación agrícola se convirtió en una preocupación y en una prioridad evidente en determinados círculos: se trataba de formar profesionales en el que era uno de los pilares económicos del país. Buena prueba de ello es que, una vez superados los numerosos obstáculos para sacar adelante estas escuelas técnicas, se les concedieron, primero en Aranjuez y después en Madrid, amplios territorios cercanos a ambas poblaciones, que poseían además un importante valor histórico. Estos territorios habían pertenecido a la Corona, que, en mayor o menor medida, fue siempre protectora de la institución, hasta el punto de denominarse durante un período Instituto Agrícola de Alfonso XII -tal vez en un intento por recuperar, siquiera simbólicamente, el territorio que le había pertenecido.

A pesar de este apoyo, la situación política del país hizo que la dotación económica para la institución fuera insuficiente, al menos al principio, para acometer las obras y reformas que necesitó su instalación ${ }^{29}$. Este es el motivo por el que podemos afirmar que la Fábrica de Porcelana se mantuvo, salvo acondicionamientos puntuales, en su estado original durante los primeros años de su función como Escuela; que posteriormente se acometieron reformas, siempre parciales, de las que la mayor fue la que se realizó en el patio nordeste, pero que la estructura general del edificio apenas varió durante el usufructo de los agrónomos.

Un edificio, el de la Fábrica de Porcelana, que, por cierto, también aprovechó restos de su antecesor. Aunque tenemos bastante información de la producción y organización de la manufactura, su continente es poco conocido. Algunos planos y documentos escritos nos permiten apuntar que se reutilizó el edificio en torno a dos patios de la Granjilla de los Jerónimos y se construyó tan solo el cuerpo delantero -obviando, por supuesto, la adecuación de lo existente para su nuevo uso-. Nos encontramos, pues, con un mismo edificio que va creciendo y transformándose, tanto en su aspecto físico como en cuanto a su función. Su trayectoria vital terminaría con

29 Aparte de las diversas solicitudes de ampliación de presupuesto para acometer obras (consúltese, por ejemplo, AHN FC-M ${ }^{\circ}$ O__P,91), en el Real Decreto de 21 de enero de 1878 también se sugiere que, para mejorar la situación económica de la Escuela, esta pudiera beneficiarse en metálico de sus rendimientos, que entonces se ingresaban en el Tesoro Público. 
el diseño de la nueva Escuela de Agrónomos, cuya construcción se solapó con el uso del edificio anterior, de tal forma que este desapareció paulatinamente, en un proceso con una cierta similitud al de su construcción.

La conclusión final de este trabajo, que es también una respuesta a la metodología empleada, se traduce en los planos y dibujos realizados sobre la Fábrica de Loza y la Escuela de Agrónomos, que permiten estudiar la forma y situación de los edificios, y también establecer hipótesis cuando no existe un conocimiento cierto de algún dato.

\section{REFERENCIAS BIBLIOGRÁFICAS}

Alonso Martínez, Vicente (1911). Instituto Agrícola de Alfonso XII: Escuela Especial de Ingenieros Agrónomos. Memoria histórica. Madrid: Ministerio de Fomento. Disponible en: http://cdp.upm.es/webclient/StreamGate?folder $\mathrm{id}=0 \& \mathrm{dvs}=1542385165133 \sim 994 \&$ usePid1 $=$ true\&usePid2=true [Consulta: $15 \mathrm{de}$ noviembre de 2018].

Añón Feliú, Carmen (1987). Real Jardín Botánico de Madrid: sus orígenes 1755-1781. Madrid: CSIC.

Arce, José de (1911). Estación de Ensayo de Máquinas del Instituto Agrícola de Alfonso XII. Madrid: Sucesores de Rivadeneyra.

Cartañà Pinén, Jordi (2005). Agronomía e ingenieros agrónomos en la España del siglo $X I X$. Barcelona: El Serbal.

Chías Navarro, Pilar (1986). La Ciudad Universitaria de Madrid. Madrid: Universidad Complutense.

Escuela Técnica Superior de Ingenieros Agrónomos (1980). Historia de las Escuelas Técnicas de Ingeniería Agronómica 1855-1980. Madrid: Escuela Técnica Superior de Ingenieros Agrónomos.

Fernández Paradas, Antonio Rafael (2009). Los hermanos Zuloaga y su aportación a la fábrica de productos cerámicos "La Moncloa". Nuevas piezas para su estudio. Anales del Instituto de Estudios Madrileños, n. 49, pp. 331-363.

Fernández Talaya, María Teresa (1999). El Real Sitio de La Florida y La Moncloa: evolución histórica y artística de un lugar madrileño. Madrid: Fundación Cajamadrid.

González Casas, José Luis y Muñoz Hernández, Jara (2018). Drawing for heritage dissemination. The birth of Madrid's Ciudad Universitaria. International Journal of Heritage Architecture, n. 2 (2), pp. 359-371. DOI: 10.2495/HA-V2-N2-359-371.

González Casas, José Luis y Muñoz Hernández, Jara (2020). The urban and environmental Impact of Madrid's Ciudad Universitaria: A comparison between the first Campus and the post-war Campus. International Journal of Sustainable Development and Planning, n. 15 (6), pp. 885-892. DOI: 10.18280/ijsdp.150612. 
González Casas, José Luis y Ortega Vidal, Javier (2018). La Ciudad Universitaria de Madrid: precedentes y proyecto de un ámbito urbano. En Rodríguez-López, Carolina y Muñoz Hernández, Jara (coords.). Hacia el centenario. La Ciudad Universitaria de Madrid a sus 90 años. Madrid: Ediciones Complutense, pp. 69-99.

López Bustos, Carlos (1986). Tranvías de Madrid, Madrid: Aldaba.

López y Malta, Cándido (1988 [1868]). Historia descriptiva del Real Sitio de Aranjuez escrita en 1868 sobre lo que escribió en 1804 D. Juan Álvarez de Quindós. Aranjuez: Doce Calles (ed. facsímil).

Losada Villasante, Alberto et al. (2006). Una pequeña historia alrededor del espacio de hidráulica y riegos en la Escuela de Ingenieros Agrónomos de Madrid. Biblio 3W, Revista Bibliográfica de Geografía y Ciencias Sociales, 11 (678), 1-36. Disponible en: http://www.ub.edu/geocrit/b3w-678.htm [Consulta: 10 de noviembre de 2018].

Madoz, Pascual (1848). Madrid. Audiencia, provincia, intendencia, vicaría, partido y villa. Madrid: Imprenta del Diccionario geográfico-estadístico-histórico de D. Pascual Madoz.

Maldonado Polo, J. Luis (2004). Liberalismo y enseñanza agrícola. La Sociedad Económica Matritense y la red nacional de cátedras de agricultura. Anales del Instituto de Estudios Madrileños, n. 44, pp. 181-202.

Marín, Francisco José et al. (1999). La intervención arqueológica en el Parque del Retiro (Huerto del Francés). En Manufactura del Buen Retiro. 1760-1808. Madrid: Museo Arqueológico Nacional, pp. 129-144.

Moya González, Luis (2008). La Ciudad Universitaria de Madrid: un proyecto urbanístico de principios del siglo XX contemplado hoy. En López Ríos, Santiago y González Cárceles, Juan Antonio (coords.). La Facultad de Filosofía y Letras de Madrid en la Segunda República. Arquitectura y Universidad durante los años 30. Madrid: SECC, Ayuntamiento de Madrid.

Muñoz Hernández, Jara (2017). La Escuela de Agrónomos en La Flamenca. Anales del Instituto de Estudios Madrileños, n. 57, pp. 81-103.

Muñoz Hernández, Jara (2018). La Escuela de Ingenieros Agrónomos en La Florida-Moncloa. En Rodríguez-López, Carolina y Muñoz Hernández, Jara (coords.). Hacia el centenario ..., pp. 101136.

Muñoz Hernández, Jara y González Casas, José Luis (2019a). Traces and scars: The reconstruction of Madrid's Ciudad Universitaria after the Spanish Civil War. WIT Transactions on The Built Environment, n. 191, pp. 211-222. DOI: 10.2495/STR190181.

Muñoz Hernández, Jara y González Casas, José Luis (2019b). La Ciudad Universitaria de Madrid: destrucción y reconstrucción de un paisaje universitario. Congreso Internacional "Patrimonio cultural y catástrofes: Lorca como referencia". Madrid: Instituto del Patrimonio Cultural de España, pp. 335-343.

Ordóñez, Leticia (1984). La Real Fábrica de Porcelana de La Moncloa. Villa de Madrid, n. 80, pp. 41-54. Disponible en: http://www.memoriademadrid.es/buscador.php? accion=VerFicha\&id=19259\&num_id=1\&num_total=4 [Consulta: 11 de noviembre de 2018]. 
Ortega Vidal, Javier, Martínez Díaz, Ángel, Muñoz de Pablo, María José (2011). El dibujo y las vidas de los edificios. EGA: Revista de Expresión Gráfica Arquitectónica, n. 18, pp. 50-63.

Pérez-Villamil, Manuel (1904). Artes e industrias del Buen Retiro. Madrid: Sucesores de Rivadeneyra.

Pérez-Villanueva Tovar, Isabel, La Ciudad Universitaria de Madrid (1927-1931). En Rodríguez-López, Carolina y Muñoz Hernández, Jara (coords.). Hacia el centenario..., pp. 25-67.

Puche Riart, Octavio y Mazadiego Martínez, Luis Felipe (2000). Industria cerámica madrileña: Real Fábrica de Porcelana de La Moncloa. Temas Geológico-Mineros, n. 31, pp. 277-287. Disponible en: http://oa.upm.es/10178/1/moncloa.pdf [Consulta: 25 de octubre de 2018].

Rodríguez-López, Carolina (2015). Paisajes de una guerra: la Ciudad Universitaria de Madrid. Madrid: Universidad Complutense.

Rubio Celada, Abraham (2005). La fábrica de cerámica de la Moncloa en época de los Zuloaga (1877-1893). Madrid. Revista de Arte, Geografía e Historia, n. 7, pp. 223252.

Sánchez Hernández, María Leticia (1989). Catálogo de porcelana y cerámica española del Patrimonio Nacional en los palacios reales. Madrid: Patrimonio Nacional.

Sancho, José Luis (1995). La arquitectura de los Reales Sitios. Catálogo histórico de los palacios, jardines y patronatos reales del Patrimonio Nacional. Madrid: Patrimonio Nacional.

Seseña, Natacha (1995), Las Manufacturas Reales de Cerámica: Buen Retiro y Moncloa. En Anes, Gonzalo (coord.). Manufacturas Reales. Ciclo de conferencias. Madrid: Patrimonio Nacional.

Sierra Álvarez, José y Tuda Rodríguez, Isabel (2000). Sureda y la renovación de la cerámica española durante el primer tercio del siglo XIX. En Bartolomé Sureda (1769-1851). Arte e industria en la ilustración tardía. Madrid: Museo Municipal de Madrid, pp. 89-157. 
